\title{
A potential complication following endoscopic retrograde cholangiopancreatography: Subcapsular hepatic hematoma.
}

\author{
Tsung-Hsun Yang ${ }^{1 \#}$, Kwei-Ming Chen ${ }^{2 \#}$, Shih-Wei Huang ${ }^{3,} 4^{*}$ \\ ${ }^{1}$ Department of Internal Medicine, Division of Hepato-Gastroenterology, Chang Bing Show Chwan Memorial Hospital, \\ Lukang Town, Changhua County, Taiwan \\ ${ }^{2}$ Department of Internal Medicine, Division of Gastroenterology, Show Chwan Memorial Hospital, Changhua, Taiwan \\ ${ }^{3}$ Department of Surgery, Division of General Surgery, Show Chwan Memorial Hospital, Changhua, Taiwan \\ ${ }^{4}$ IRCAD-Asian Institute of TeleSurgery, Show Chwan Health Care System, Changhua, Taiwan \\ \#These authors have equally contributed to this study.
}

\begin{abstract}
Endoscopic Retrograde Cholangiopancreatography (ERCP) is a technique with high success rate for diagnosis and treatment of biliary and pancreatic diseases, but haemorrhagic complications usually occurs when utilizing Endoscopic Sphincterotomy (EST) or Endoscopic Papillotomy (EPT). Here, we described the case of a 37-y-old female whose Common Bile Duct (CBD) stones were removed via ERCP and EPT due to dilated gallbladder and CBD obstruction. However, the patient suffered from subcapsular hepatic hematoma, sepsis, acute pancreatitis after ERCP. We arranged a second ERCP, Endoscopic Naso-Biliary Drainage (ENBD) and removed stones from gallbladder and junction of CBD and Common Hepatic Duct (CHD) by the Laparoscopic Common Bile Duct Exploration (LCBDE), as well as long-term antibiotic treatment. The patient then had a good condition of postoperative recovery. Hence, it should be alarming that subcapsular hepatic hematoma could be a potential complication postERCP and is life-threatening, and we provided the experience of utilizing a number of diagnostic techniques and a multidisciplinary approach of therapy strategies for resolving such complication successfully.
\end{abstract}

Keywords: Subcapsular hepatic hematoma, Common bile duct, ERCP, Complication.

Accepted on June 07, 2018

\section{Introduction}

Endoscopic Retrograde Cholangiopancreatography (ERCP), which was introduced into the field of gastroenterology, hepatology and hepato-pancreatico-biliary surgery, has progressed to be an important and essential diagnostic and therapeutic tool for biliary and pancreatic diseases but haemorrhagic complications usually occurs when utilizing Endoscopic Sphincterotomy (EST) or Endoscopic Papillotomy (EPT) [1-4]. The complication of subcapsular hepatic hematoma after conducting ERCP is uncommon and a likely life-threatening situation in which few cases was reported in the world [5]. With respect to currently related literatures, they provide good experiences to treat subcapsular hepatic hematoma post-ERCP. Here, we present a case of subcapsular hepatic hematoma after ERCP implementation, and provided active treatments in which multiple stones were removed from the patient.

\section{Case Report}

A 37-y-old female had mild epigastric pain and visited our gastrointestinal unit on November $8^{\text {th }}, 2015$. The patient also complained of nausea, vomiting, diarrhoea and chest tightness at that time. The medical records showed that she has no diabetes mellitus, hypertension and hepatitis $\mathrm{B}$ or $\mathrm{C}$, but she was conducted tubal ligation surgery $1 \mathrm{y}$ ago. Physical examination revealed mild scleral icterus, hyperactive bowel sound in abdomen and focal tenderness over epigastric region. Initial blood tests presented the elevated total bilirubin (1.2 $\mathrm{mg} / \mathrm{dl}$ ) and neutrophils (81\%). Chest or abdomen displayed no evidence of abnormality.

Therefore, we arranged panendoscopy examination on November $9^{\text {th }}$ and the report showed reflux esophagitis and superficial gastritis over antrum. Abdominal ultrasound examination revealed hypoechogenic lesion around gallbladder and duct system, fatty liver, Common Bile Duct (CBD) dilatation, lymph node enlargement and extension to para 
arotic area, and multiple calculi in the gallbladder and CBD (Figure 1). Furthermore, the patient had intermittent upper quadrant pain and mild fever, and thus we prescribed cefmetazole as antibiotic therapy. We further arranged Magnetic Resonance Cholangiopancreatography (MRCP) on November $12^{\text {th }}$ revealing clearly mild biliary obstruction caused by proximal CBD stone (Figure 2), and the images indicated heterogenous low signal change of liver parenchyma that may be due to dilated intrahepatic ducts at proximal CBD and thick-walled gallbladder with multiple filling defects.

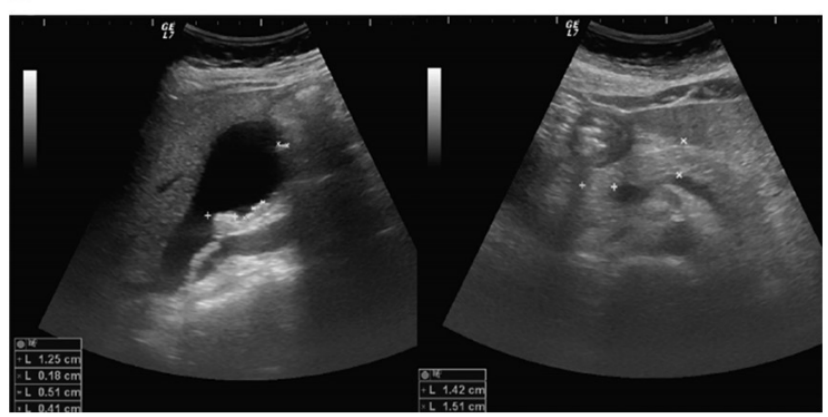

Figure 1. The abdomen ultrasound image of hypoechogenic lesion around: (A) Gall bladder; (B) Duct system.

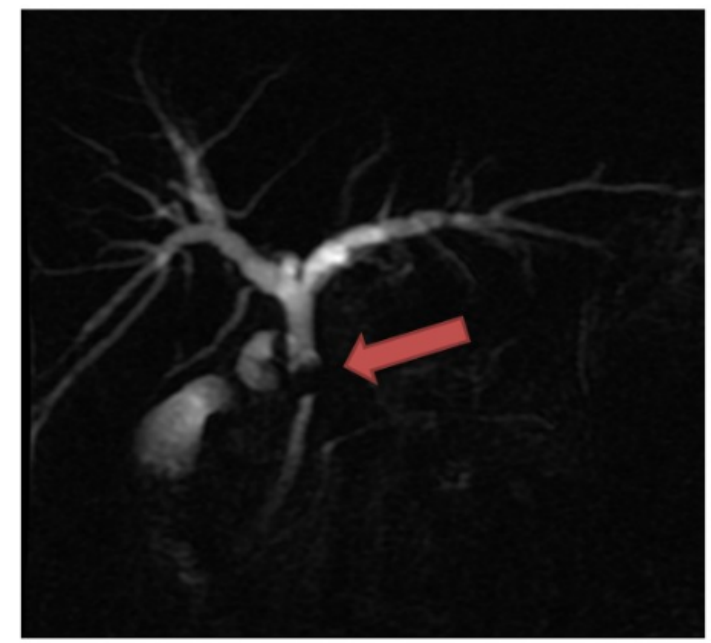

Figure 2. The MRCP image showing biliary obstruction with proximal $C B D$ stone (red arrow).

For the further treatment based on the diagnosis, we utilized ERCP with EPT for retrieval of the CBD stone on November $13^{\text {th }}$. However, after the procedure on November $17^{\text {th }}$, the patient's body temperature was elevated up to $39.8^{\circ} \mathrm{C}$, elevated total bilirubin $(5.2 \mathrm{mg} / \mathrm{dl})$ and neutrophils (91\%), and whole abdominal distension with dull pain. Thus, we arranged a second ERCP accompanied by Endoscopic Naso-Biliary Drainage (ENBD) on November $18^{\text {th }}$ (Figure 3). Surprisingly, the patient was almost in syncope on the next day (November $\left.19^{\text {th }}\right)$, and abdomen CT scan showed suspected right lobe of subcapsular hepatic hematoma that could be due to small artery perforation (Figure 4). Additionally, mild pancreatitis and aerobilia was also observed (Figure 4), and angiography displayed no active bleeding, but the haemoglobin level declining from 11.9 to $5.9 \mathrm{~g} / \mathrm{dl}$.

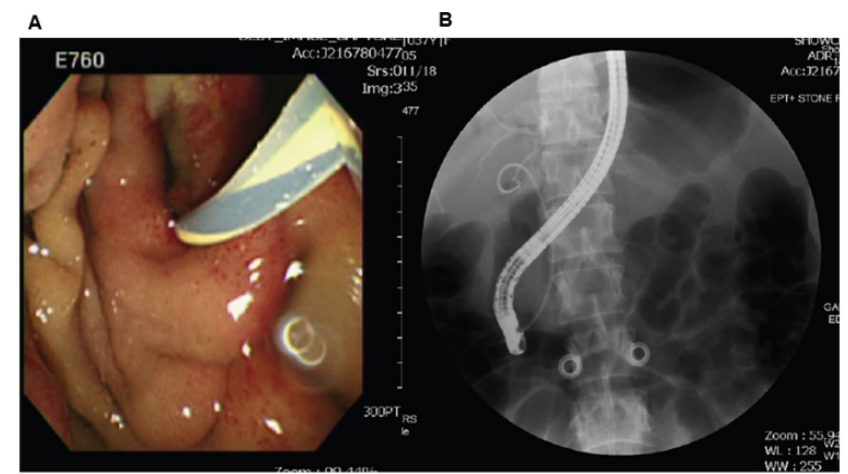

Figure 3. Image from a patient with biliary obstruction treated with ENBD. (A) Endoscopic view of the guidewire; (B) External drainage system that inserts a pig-tail drain tube into $C B D$.

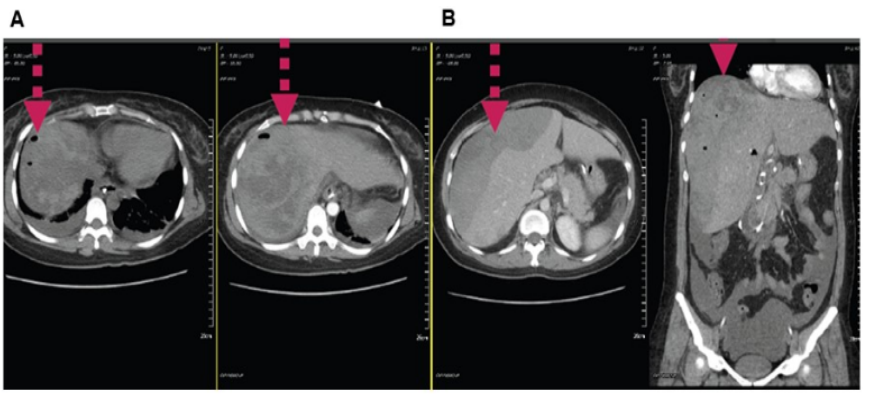

Figure 4. Computed tomography scan imaging displays: (A) Artery perforation; (B) Subcapsular hepatic hematoma on the surface of the right lobe of the liver in upper abdomen.

Consequently, the patient was transferred to Surgical Intensive Care Unit on November $20^{\text {th }}$, and about 1,200 ml sanguineous ascites was drained away from right lateral abdomen under echo guide. We also prescribed meropenem as the long-term antibiotic therapy, and supplied blood transfusion and central venous pressure in situ. Chest posterior to anterior view indicated pulmonary edema, segmental atelectasis and minimal pleural effusion, and the haemoglobin level increased from 5.9 to $10.3 \mathrm{~g} / \mathrm{dl}$.

Finally, choledocholithotripsy with T-tube, cholecystectomy and intraoperative choledoscope with $\mathrm{CBD}$ stone extraction were performed following the explorative laparoscopy, the Laparoscopic Common Bile Duct Exploration (LCBDE) on $30^{\text {th }}$ November. In the operative setting, subcapsular hepatic hematoma with capsular rupture, and multiple and small yellowish stones in gallbladder cavity, a $1.0 \mathrm{~cm}$ diameter of stone in the junction of Common Hepatic Duct (CHD) and CBD (Figure 5), were found. Therefore, the cause of syncope was further proven to be subcapsular hepatic hematoma postERCP. Our final diagnosis consisted of infections of gramnegative bacteria, Klebsiella pneumoniae, and acute pancreatitis. The patient gradually recovered and was discharged in good condition. Written informed consent was obtained from her family. 


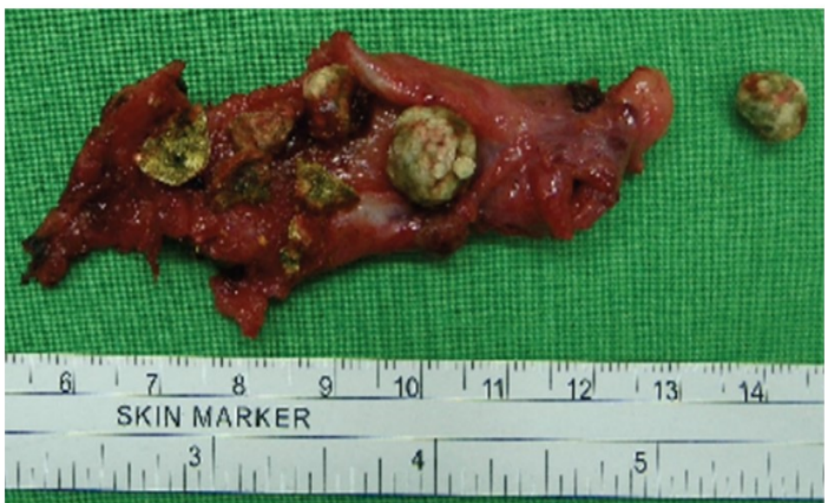

Figure $5.1 .0 \mathrm{~cm}$ diameter of stone in the junction of $C H D$ and $C B D$ after ERCP implementation.

\section{Discussion}

So far there are 53 cases of subcapsular hepatic hematoma complication in the world including our case that are mostly caused by wire-guide ERCP for the diagnosis and treatment of bile duct-related disorders, especially in removal of $\mathrm{CBD}$ stone, biliary obstruction and cholangiocarcinoma surgical therapy. In these cases, most patients survived and only three patients deceased [6-10]. Although the mortality rate of complication could be low, it is still potentially lifethreatening. In our case, we also have an uncommon event of subcapsular hepatic hematoma post-ERCP, and then supplement of antibiotic was conducted. In addition, we removed multiple stones from gallbladder and junction of CHD and CBD by using LCBDE. Overall, our diagnosis consisted of infections of Gram-negative bacteria, $K$. pneumoniae, found in the normal flora of intestines and thus not hospital acquired, and acute pancreatitis [11].

Previous studies have explained that subcapsular hepatic hematoma was related to infections from accidental puncture with non-sterile guide-wire and resulting in rupture of small intrahepatic vessels during endoscopy procedure in all cases worldwide [3]. Interestingly, the systematic review and metaanalysis reported that the prophylactic effectiveness of the nonsteroidal anti-inflammatory drugs can reduce the pancreatitis following ERCP [12]. Moreover, on chest X-ray, we first found segmenta atelectasis and diffuse or multifocal airspace disease, pulmonary edema and pleural effusions after ERCP.

In summary, subcapsular hematoma could be treated safely with conservative treatment. In this this study, we provided the experience that appropriate antimicrobial therapy and close monitoring was appropriate for this situation. Furthermore, we were able to perform laparoscopic surgery once the patient was stabilized, proving the self-limiting nature of this emergent situation. In conclusion, it should be alarming that subcapsular hepatic hematoma could be a potential complication postERCP and is life-threatening, and we provided the experience of utilizing a number of diagnostic techniques and a multidisciplinary approach of therapy strategies for resolving such complication successfully.

\section{Conflicts of Interest}

The author declares no conflict of interest.

\section{Acknowledgement}

We would like to acknowledge the editorial service provide by the Research Assistant Center, Show Chwan Health Care System, Taiwan.

\section{References}

1. Santo MA, Domene CE, Riccioppo D, Barreira L, Takeda FR, Pinotti HW. Common bile duct stones: analysis of the video laparoscopic surgical treatment. Arq Gastroenterol 2012; 49: 41-51.

2. González-López R, García-Cano E, Espinosa-González O, Cruz-Salgado Á, Montiel-Jarquin ÁJ, Hernández-Zamora V. Surgical treatment for liver haematoma following endoscopic retrograde cholangiopancreatography: An unusual case. Cir Cir 2015; 83: 506-509.

3. Zizzo M, Lanaia A, Barbieri I, Zaghi C, Bonilauri S. Subcapsular hepatic hematoma after endoscopic retrograde cholangiopancreatography: A case report and review of literature. Medicine (Baltimore) 2015; 94: e1041.

4. Freeman ML, Nelson DB, Sherman S, Haber GB, Herman ME, Dorsher PJ, Moore JP, Fennerty MB, Ryan ME, Shaw MJ, Lande JD, Pheley AM. Complications of endoscopic biliary sphincterotomy. N Engl J Med 1996; 335: 909-918.

5. Orellana F, Irarrazaval $\mathrm{J}$, Galindo $\mathrm{J}$, Balbontin $\mathrm{P}$, Manríquez L, Plass R, Araya R, Rios H, Saenz, R. Subcapsular hepatic hematoma post ERCP: a rare or an underdiagnosed complication? Endoscopy 2012; 44: 108-109.

6. Corazza LR, D’Ambrosio L, D’Ascoli B, Dilorenzo MF. Subcapsular hepatic hematoma. Is it still an unusual complication post ERC? Case report and literature review. Gastroenterol Hepatol 2017; 6: 00211.

7. Del Moral Martínez M, Delgado Maroto A, Cervilla Sáez de Tejada ME, Casado Caballero FJ, Salmerón Escobar FJ. Hepatic hematoma after ERCP: two new case reports. Rev Esp Enferm Dig 2017; 109: 470-473.

8. Soler Humanes R, Suárez Muñoz MÁ, García García B. A post-endoscopic retrograde cholangiopancreatography subcapsular hepatic hematoma. Rev Esp Enferm Dig 2017; 109: 803.

9. De la Maza Ortiz J, García Mulas S, Ávila Alegría JC, García Lledó J, Pérez Carazo L, Merino Rodríguez B, González Leyte M, Nogales Ó. Subcapsular hepatic haematoma after endoscopic retrograde cholangiopancreatography. A rare complication with high morbidity and mortality. Gastroenterol Hepatol 2018.

10. Caroço TV, Louro JM, Coelho MI, Costa Almeida CE. Rare case of hepatic haematoma following endoscopic 
retrograde cholangiopancreatography. BMJ Case *Correspondence to

Rep 2018.

11. Ryan KJ, Ahmad N, Alspaugh JA, Drew WL, Lagunoff M, Pottinger P, Reller LB, Reller ME, Sterling CR, Weissman S. Sherris medical microbiology (7th Ed.). McGraw Hill Education 2018.

12. Sajid MS, Khawaja AH, Sayegh M, Singh KK, Philipose Z. Systematic review and meta-analysis on the prophylactic role of non-steroidal anti-inflammatory drugs to prevent post-endoscopic retrograde cholangiopancreatography pancreatitis. World J Gastrointest Endosc 2015; 7: 1341-1349.

Shih-Wei Huang

Department of Surgery

Division of General Surgery

Show Chwan Memorial Hospital

Changhua

Taiwan 